\title{
REVITALIZING ANTHROPOLOGY IN EAST AFRICA: \\ THE BIRTH OF EAAA
}

\author{
Mwenda NTARAngw! \\ Box 43795, Nairobi, Kenya \\ Tel. 072513500 \\ E-mail: mnta@africaonline co.ke
}

\section{Introduction}

ast Africa is known the world over for its extensive contribution to the history of humankind especially through the work of paleontologists and other archaeologists. Yet if one asked an average East African what anthropology is one is likely to be told that it is something to do with looking at old bones or one will have no clue all together. Such responses are instructive of the way anthropology and anthropologists have operated in East Africa specifically and Africa generally. First, antiropoiogy as a discipline is another of the Western social science disciplines that entered the region through the main channel of colonialism. It indeed, reflects a kind of duality that is most likely to have schizophrenic adherents given both the British and American influences. The former which was a major player in the development of East African social sciences as colonizer adheres to a brand of anthropology that clearly separates the discipline into archaeology (which is often seen as a unit of history) while the latter which has become a major player in world scholarship because of its increased economic and political power favors a discipline that combines anthropology into the four fields of linguistic, cultural, physical, and archaeological anthropology. Thus one is able to find an American trained anthropologist in the University of Dar es Salaam unable to use his full anthropological training because he is in an archaeology unit that was structured to augment the work of historians. Second, anthropology has had its share of bad press in Africa for many years because of its association with colonialism although the same critiques have not been extended to other disciplines that are equaliy guilty of promoting Western superiority over Africa. This led to many anthropologists being unable to assert themselves in their own institutions where no specific departments of anthropology were present and also because of fear of being ridiculed as products of a colonial discipline. But things have changed in the recent past and anthropology has started becoming a respected discipline in the region. Indeed, many government offices, tertiary institutions, and NGO's have realized the critical role that anthropology can play in the social, political, and economic 
understanding and development of our communities. Inarguably anthropology is the only discipline that can boast of a structure and history of studying and understanding the entirety of human existence which is incredibly critical in Africa today--a continent that continues to be seen as a gone case in matters of global concern. It is the realization of this critical role that anthropology can and will continue to play in Africa that a professional association that would bring together anthropologists in East Africa was deemed necessary. Having returned in the late 90's from the US armed with a doctoral degree in cultural anthropology I was keen on making a major contribution to the discipline in East Africa but was not sure if there were many other anthropologists who had the same passion for the discipline as I had. I guess much of it had to do with the freshness of my training as well as the relevance I saw for the discipline in explaining and understanding some the socio-cultural issues that were current in Kenya at that time. This passion translated into the birth of the Eas! African Anthropological Association (EAAA) in Nairobi mid 2001.

\section{The East African Anthropological Association}

The idea to form an association actually begun as a dream of trying to establish if there were other anthropologists in East Africa interested in regular exchange of ideas electronically and through conferences. To test the waters I bought space in the regional weekly newspaper The East African for Monday March 12, 2001, and put up the following message:

\section{CaLling on ANTHRopologists In EASt Africa}

$\Leftrightarrow$ Are you a trained anthropologist resident in East Africa?

$\Rightarrow$ Would you like to be part of a professional body?

$\Rightarrow$ Are you teaching and conducting research in and on East Africa?

$\Rightarrow$ Do you have papers and manuscripts you would like to publish?

$\Rightarrow$ Would you like to meet with other anthropologists and exchange ideas or just socialize?

Then send your current $\mathrm{CV}$ including a phone number and email address to:

Mwenda Ntarangwi, Ph.D.

P.O. Box 43795, Nairobi, Kenya

Tel. 072513500

E-mail: mnta@africaonline.co.ke 
Please share this information with other anthropologists known to you who may not see this ad.

Thank you and looking forward to hearing from you soonest possible.

From this ad, I was able to collect over forty-five names and addresses of anthropologists and other social scientists interested in anthropological work in East Africa. With this kind of interest it was apparent there was quorum for an association. This is why in consultation with a few anthropologists in Nairobi the idea of a first meeting of anthropologist in East Africa was mooted and the date tentatively set for June 2001. Thus the East African Anthropological Association (EAAA) was formed at this first meeting of anthropologist in East Africa held in Nairobi June 22-23, 2001. At this meeting EAAA pledged to be actively involved in promoting anthropology as a discipline in tertiary institutions as well as encourage more anthropological research in the East African region. The meeting that brought together anthropologists working in the region to dialogue and increase the visibility of the discipline drew participants from major universities in the region, NGOs, the private sector, and other social scientists keen on learning more about anthropological work. The main conclusion at this meeting was that although anthropology is taught in the major universities in Kenya, Uganda and Tanzania, it is done poorly. It was further noted that the critical role that anthropology and anthropologists are meant to play in the holistic development of training and research in the region is not realized. For instance, many anthropologists hide in sociology departments, others in social work, while others are in institutes that do not clearly highlight anthropology as their main operative discipline. There are also many anthropologists in the NGO world and other private sectors that are not recognized or even aware of the enormous resource they are were they to share it with others interested in the discipline and its operations. Some of the anthropologists are in government ministries as cultural officers while others are teaching in secondary schools or have altogether abandoned the discipline and/or engaged in other unrelated activities. Specifically, there is not much anthropology in East Africa's tertiary institutions. At the University of Dar-es-salaam in Tanzania, for instance, anthropology is taught as a course in the department of archeology; at Egerton University in Kenya, there is a department of Sociology and Anthropology but with no member of the teaching staff who is a trained anthropologist; and at Makerere University in Uganda, there is no anthropology department but rather anthropologists mostly working in the department of sociology and various research institutes. There are many other examples of how anthropology as a discipline is underrepresented in our tertiary institutions despite its importance in explaining the current socio- 
economic realities experienced by our communities and nations. It is with this in mind that EAAA is set to move quickly to change this sorry state of affairs. The first task of EAAA is to establish the number of anthropologists working in the East African region, their specific training, resources they use in training their students and in dispensing their duties, and how best to harness the power of anthropology as a discipline can enable them move our countries to a more informed and manageable future. One way of bringing together these ideas and skills is through shared workshops and conferences.

\section{REGIONAL CONFERENCES AND / OR WORKSHOPS}

Key to the development of EAAA is regional conferences and workshops that will be held in one of the three countries in East Africa alternately. The second EAAA workshop will coincide with the $12^{\text {th }}$ annual Pan African Anthropological Association's (PAAA) meeting in Nairobi August 4-10, 2002. This meeting which will bring together anthropologists working in the East African region as well as the continent of Africa at large will be a showcase for the role of anthropology in the future of Africa. The EAAA participants who will have special sessions during the PAAA conference, will be drawn from a pool of those especially teaching anthropology at the various universities in the region with the mandate to critically review their teaching methods and materials, the specific courses offered at their universities and their relevance to the attendant communities, and create networks that will enable not only exchange of ideas and materials for teaching but also expertise. In recognition of the importance of proper grounding in concepts and meanings in anthropological work, the Nairobi workshop will focus on the two most important areas in the development of anthropology-- training and research. The universities in the region are besieged by many problems including inadequacy of qualified personnel, lack of reference materials and funding for research, and yet required to generate their own income and move away from government funding. This has thus turned many into business entities that often neglect basic requirements for quality educational programs. Further, problems in training reflect negatively on research and this can be deduced from the low participation by anthropologists in matters and areas critical to the social and cultural realities of the East African region. By focusing on training and research, the workshop will bring together key scholars in the region to look at these and other issues for discussion and follow-up. Special papers related to actual teaching and research experience will be prepared and presented at the workshop. Participants will then be invited to critically analyze courses taught in the universities, the capacities, reference 
materials and networks with the aim of making them context specific. The main sub-disciplines to be discussed include, but not limited to, medical, economic, archaeological, physical/biological, cultural, political, and linguistic anthropology. Academics currently teaching these courses will be identified and requested to prepare a summary of the content and challenges encountered in each country. This exercise will make available to the participants sources of information (such as reading lists and course contents), linkages with other scholars and innovative ways of teaching and conducting research.

To enhance research and applied anthropology, anthropologists working with NGOs, those conducting research collaboratively with local and international scholars, as well as those teaching research methods courses in our universities, will be called upon to make presentations on their own experiences, skills, and projections, to be shared with other participants and their respective institutions.

This workshop will create a forum that will make public the role of anthropology in East Africa; will strengthen national, regional and institutional networks of anthropological knowledge and exchange; and, inform key individuals and organizations in East Africa of EAAA and the role of anthropology in both public and private arenas. After the $2^{\text {nd }}$ conference presentations, the association will then compile all the papers and notes from the meetings and prepare a document that will become a benchmark for future anthropological work in the region. It is thus imperative that participants prepare their presentations with the understanding that they are setting up the pace that will guide future anthropological work in the East African region.

\section{PRospects AND ChALlenges for EAAA}

This association comes at a time when the East African region is undergoing tremendous socio-cultural changes that need to be critically analyzed, understood, and explained for the benefit of the community. It is also a time when university education has become a business putting a lot of emphasis on increased enrolment through offering courses that are on demand. However, limited focus has been laid on the quality of the content, methodology and research programs introduced as a result. The $2^{\text {nd }}$ conference of EAAA seeks to address this anomaly by bringing together scholars in the region to consult widely and discuss ways of improving anthropology teaching and research in the region.

Besides being an academic discipline, anthropology is also a method of looking critically and explaining complex processes such as globalization that seem to heavily impinge on our day to day interactions. Moreover, 
anthropologists have for long looked at contemporary social problems and realities, unearthed received and taken-for-granted "truths," to give many of its audiences a better understanding of their lives and social circumstances. Anthropologists can play a key role in the region in understanding factors that shape access to quality education, health and other services. Therefore, a regional association that brings together scholars to engage collaborative work and exchange of ideas and expertise will play a key role in shaping this process. What is more, with a continental participation due to the P.AAA meeting which coincides with the EAAA second conference, East African anthropologists will have a wider and invigorating participation.

Even with its future looking bright, the association is not with its own startup problems. At the beginning of EAAA there were numerous challenges. One major one is commitment from anthropologists in the region. Many people are comfortable with receiving a well-planned and organized association without any desire to participate in its creation. Indeed, many were very keen to be in communication just before the first meeting but once the association was formed and roles distributed, few carried through the initial enthusiasm. Indeed, the shifting of the $2^{\text {nd }}$ conference from the initial venue in Arusha in March 2.002 to Nairobi in August 2002 was as a result of little enthusiasm from our colleagues in Tanzania who were meant to spearhead the local arrangements and planning for the conference.

There are other anthropologists who constantly spell doom on the association citing past experiences of associations that have collapsed. I received such an email from anthropologists in the region who felt that this initiative was a waste of time as he had seen many others go down in the hands of unscrupulous people. Granted that this has indeed happened, it would be incumbent upon every anthropologist to try and make an effort to support a professional association instead of showering it with messages of doom at its initial stages. Maybe it is in order to mention that in only its second year of operation EAAA has already started taking great strides in defining anthropological work in the region. It has already two volumes of a newsletter-anthropolojia-to its name and is working towards closer collaboration with the Pan African Anthropological Association (PAAA), the Association of Social Anthropologist in the UK and the Commonwealth (ASA) and the International Social Science Council (ISSC). But we cannot overlook one other impediment, that of a major cancer that has crippled academic work in the region in the form of over-dependence on the West for not only funding but also fresh ideas. If the EAAA is to make any lasting marks on the map of anthropology in the world, these and many other issues have to be addressed and handled openly and candidly by all members and affiliates. 